\title{
TACNA Y ARICA: COMPETENCIA Y COMPLEMENTACIÓN ECONÓMICA
}

\author{
Washington Zeballos Gámez
}

\author{
R E S U M E N
}

Tacna (Perii) y Arica (Chile) son dos ciudades fronterizas que han conformado históricamente un solo espacio geoeconómico y que mantienen relaciones económicas muy activas, sin embargo, en los últimos años, los gobiernos de ambos paises han pugnado por fomentar en sus respectivas zonas fronterizas mejores condiciones de competitividad, dejando en un segundo plano las acciones de complementación económica que podrian generar beneficios reciprocos y coadvuvar al desarrollo de , ambas localidades:

\begin{abstract}
A B S T R A C T
Tacna (Perú) and Arica (Chile) are border cities which are located on the same geographic and economical area. They keep a very active economical relationship; however, on later years, the governments of both countries have priorized competitive strategies on their border zones, but economical cooperation has been put on second place, even though the cooperation actions could improve the economical situation of both cities.
\end{abstract}

\section{MARCO DE REFERENCIA}

Las fronteras latinoamericanas deben ser áreas de encuentro e intercambio entre los paises, por lo tanto, la integración fronteriza constituye un proceso espacialmente delimitado, que debe promover la cooperación económica asi como el intercambio social y cultural. Por supuesto, se parte de la premisa que el crecimiento económico y social de las zonas fronterizas debe descansar fundamentalmente en el esfuerzo nacional y, complementariamente, en las relaciones cooperativas que un pais establece con sus vecinos.

Las políticas de integración fronteriza vienen a ser el conjunto de medidas y acciones que un Estado se propone ejecutar, de acuerdo con su vecino limítrofe, para un sector de su frontera común. Como tal, se manifiestan bajo la forma de entendimientos

\section{Economista.}

de nivel gubernamental, de decisiones en cada nivel nacional, o por las actividades que se promueven o permiten en torno a aquellos limites. Sin embargo, debe distinguirse la política nacional relativa a las áreas de frontera, de la politica de integración fronteriza. La distinción básica reside en que la última se da en un contexto de articulación binacional.

En América Latina, las politicas nacionales de frontera, desvinculadas completamente de las adoptadas por el pais vecino, han demostrado cierta insuficiencia para mejorar la calidad de vida de las poblaciones circundantes, aun cuando se haya contribuido a consolidar el ámbito de soberania nacional. Por eso es que las relaciones binacionales, basadas en acciones articuladas y conjuntas, pueden muy bien sostener la solidez de las medidas adoptadas por cada uno de los países para sus áreas fronterizas.

En consecuencia, en el marco de una integración bilateral, una política fronteriza se orientará a tornar más fluidas las relaciones de vinculación: en lo económico, a liberalizar el intercambio de alcance 
local y agilizar y facilitar el comercio internacional que transita por el punto fronterizo. En el campo social, a promover los vínculos entre las comunidades vecinas, a cooperar en asuntos sanitarios, educativos, a procurar un manejo racional del medio ambiente, y a dar vitalidad a las expresiones culturales de ese ámbito.

En todos los casos, al determinarse la necesidad o conveniencia de la integración fronteriza debe reconocerse objetivos que son propios de las comunidades locales y de la relación binacional y, asimismo, estrategias de competitividad y complementariedad que deben consolidar el desarrollo de las zonas de frontera contiguas.

\section{COMPETENCIA ECONÓMICA}

En el contexto de la globalización de la economía mundial, las politicas nacionales de frontera de los paises, generalmente, privilegian la competitividad de sus zonas fronterizas y, prestan menor atención, a las posibilidades de complementación que existen entre dichas áreas. Evidentemente, los intereses de cada nación prevalecen desmesuradamente sobre los intereses integracionistas de la Gran Patria Latinoamericana.

Además de las ventajas comparativas que exhiben cada uno de los paises en sus zonas de frontera, hay una preocupación por generar ventajas competitivas que les permitan mejores condiciones de desarrollo para dichas zonas; ventajas que devienen en varios casos, en relaciones de «agresión» o "dependencia» económica en favor de la frontera de un pais, pero en claro perjuicio para la del pais vecino.

Un caso típico de lo señalado lo constituyen las relaciones fronterizas de Perú y Chile, y concretamente, entre las ciudades de Tacna y Arica separadas apenas por $50 \mathrm{Km}$. de distancia, pero unidas por un permanente tránsito de personas y de bienes que dinamizan las economias de ambas localidades. Las relaciones de competitividad entre una y otra zona de frontera se han basado en programas de crecimiento económico unilaterales que ejecutan cada pais y que supuestamente contribuyen a la seguridad y soberania nacionales.

\subsection{FRONTERA NORTE DE CHILE}

En las últimas décadas, el Estado chileno ha procurado el desarrollo económico de su frontera norte a través de diferentes medidas tendientes a dotarle de mejores condiciones para competir. especialmente ofreciendo estimulos e inafectaciones de carácter tributario, para atraer mayores inversiones en Arica y contrarrestar los beneficios otorgados a Tacna en el otro lado de la frontera. Entre otros incentivos a los sectores industrial y comercial destacan los siguientes:

\section{a) Régimen de Zona Franca}

La normas que rigen las zonas francas en Chile, se encuentran contenidas en el Decreto No.341 de 1977. El Artículo 27 de la Ley de Zonas Francas señala: «El régimen preferencial establecido para la Zona Franca de Iquique será aplicable a las empresas industriales manufactureras instaladas o que se instalen en Arica».

Los principales beneficios tributarios de la Zona Franca en Arica son los siguientes:

- La exención del pago de aranceles de importación, del impuesto al valor agregado (IVA) y del impuesto de primera categoria que grava las utilidades de las empresas.

- Los productos manufacturados en Zona Franca que se venden a la I Región (Iquique, Arica y Parinacota) están exentos del pago de aranceles de importación y del IVA.

- No pagan IVA las materias primas nacionales que ingresen a zona franca industrial para su transformación.

\section{b) Beneficios Adicionales para la Inversión en Arica}

- Bonificación a la contratación de mano de obra, otorgada por el Estado a los empleadores en Arica.

- Bonificación a la inversión o reinversión que se otorga a las inversiones o reinversiones en activos fijos de pequeños o medianos productores de bienes y/o servicios.

\section{c) Programa de Fomento Empresarial}

Para generar un impulso al desarrollo en la zona de Arica y Parinacota, la Corporación de Fomento de la Producción (CORFO) ha establecido una serie de instrumentos de fomento productivo a la inversión privada que se enumeran a continuación:

- Estímulo a la instalación de empresas 
intensivas en la ocupación de mano de obra residente en la zona.

- Cofinanciamiento para la realización de estudios de proyectos de inversión en la zona.

- Pago a agentes privados, promotores de inversión, para fomentar la instalación de empresas en la zona.

- Garantía al financiamiento de proyectos en la zona, otorgando cauciones solidarias al sector privado para garantizar el cumplimiento de obligaciones contraídas.

- Seguro de crédito para las empresas de la zona que requieran financiamiento.

- Canalización al sector privado de los programas de fomento productivo y de exportación operados por CORFO, SERCOTEC (Servicio de Cooperación Técnica) y PROCHILE.

Subsidio a la compra de terrenos en el Parque Industrial de Chacalluta (Arica).

\section{d) Ley Arica}

Se ha formulado un Plan Estratégico de Desarrollo de Arica y Parinacota (provincias fronterizas con Perú) y se ha promulgado en 1995 la Ley Arica, la misma que establece incentivos para las mencionadas provincias, tales como:

- Crédito Tributario a la Inversión deducible del Impuesto de Primera Categoria, equivalente al $20 \%$ hasta el año 2020.

- Centros de Exportación, áreas que gozarán de extraterritorialidad aduanera, lo que implicará devolución de impuestos a las ventas y aranceles a los productos chilenos, y suspensión de derechos e impuestos para mercancias de origen sudamericano.

- Autorización para la adquisición de inmuebles ubicados en la Comuna de Arica por nacionales de paises limítrofes.

- Autorización para que las industrias acogidas al régimen de Zona Franca, puedan recuperar el IVA que se les hubiera recargado al utilizar suministros y servicios.

- Aumento del tope máximo de compra exenta . de impuestos para viajeros procedentes de Zonas Francas de Extensión.

\subsection{FRONTERA SUR DEL PERÚ}

El Estado peruano tambièn ha dictado una serie de medidas orientadas a potenciar la competitividad de Tacna, como centro de atracción de inversiones nacionales y extranjeras, y contrarrestar a las aplicadas en Arica, poniendo énfasis en incentivos tributarios para las actividades económicas y comerciales, entre las que destacan las siguientes:

\subsubsection{Zona de Tratamiento Especial Comercial de Tacna (ZOTAC)}

La ZOTAC fue creada en 1989 e inició sus operaciones en 1990, con el objetivo de promover el desarrollo socio-económico de la región Moquegua - Tacna - Puno, mediante el fomento de las actividades comerciales, industriales y turisticas.

Sin embargo, el 29 de agosto de 1996 se ha creado sobre la base del área e infraestructura de la ZOTAC, el Centro de Exportación, Transformación, Industria, Comercialización y Servicios (CETICOS de Tacna).

Los principales beneficios que otorgaba la ZOTAC, eran los siguientes:

\section{-Régimen Comercial ZOTAC}

La comercialización de mercancías se realizaba en los depósitos francos y en la Zona de Tratamiento Especial (venta al detalle). Los usuarios de los depósitos francos estaban exonerados de todos los tributos existentes mientras que los usuarios de la Zona de Tratamiento Especial estaban exonerados del Impuesto General a las Ventas, Impuesto Selectivo al Consumo y solamente pagaban un arancel especial de $10 \%$.

\section{- Régimen Industrial ZOTAC}

Las empresas industriales y agroindustriales establecidas o que se establecían en la región Moquegua - Tacna - Puno estaban exoneradas de todos los derechos arancelarios, parancelarios, tasas, sobretasas, aplicables a la importación de insumos, que requerian para su proceso productivo, con la condición de que los productos terminados se exportaran y/o comercializaran en la ZTE, de venta al detalle.

\subsubsection{CETICOS de Tacna}

El gobierno peruano ha promulgado el 
Decreto Legislativo $\mathrm{N}^{\circ} 842$ el 29 de agosto de 1996 mediante el cual declara de interés prioritario el desarrollo de la zona sur del pais sobre la base del eje Matarani-Ilo-Tacna. Para tal efecto, se ha creado el Centro de Exportación, Transformación, Industria, Comercialización y Servicios (CETICOS de Tacna).

Durante 15 años posteriores al inicio de sus operaciones, las empresas que se constituyan o establezcan hasta el 31 de diciembre de 1998 en el CETICOS y exporten la totalidad de su producción de bienes o servicios, estarán exoneradas de todo impuesto, tasa, aportación o contribución tanto nacional como municipal.

Las mercancias que ingresen a dicho centro, desembarcadas únicamente en los puertos de llo o Matarani, se encuentran exentas del pago de derechos arancelarios y demás tributos que gravan las mismas, y podrán ser objeto de reexpedición al exterior. Además, se extiende al CETICOS de Tacna el beneficio del arancel especial del $10 \%$ para las mercancias importadas que se vendan al detalle en la ciudad de Tacna.

\subsubsection{Inversión Extranjera en Zonas de Frontera}

Se ha declarado de necesidad nacional la inversión privada nacional y extranjera, en actividades productivas realizadas o por realizarse en las zonas de frontera del Perú. Asimismo, las personas naturales y jurídicas extranjeras podrán adquirir concesiones y derechos sobre minas, tierras, bosques, aguas, combustibles, fuentes de energia y otros recursos que sean necesarios para el desarrollo de sus actividades productivas, dentro de los $50 \mathrm{Km}$ de las fronteras del Perú, previa autorización de las instancias correspondientes.

\subsubsection{Incentivos por Zona de Frontera}

La Ley de Industrias No. 23407 establece la exoneración del Impuesto General a las Ventas a las empresas industriales instaladas en zonas de frontera.

En suma, se puede observar que los resultados de esta 'competencia' entre las fronteras norte de Chile y sur del Perú, ha provocado desequilibrios e inestabilidad, debido a que, tanto Tacna como Arica han basado su desarrollo en la actividad comercial, la cual ha estado sujeta a los vaivenes del mercado internacional, a las diferencias cambiarias y de precios de ambos países, provocando alternadas épocas de estancamiento o crecimiento, en beneficio o perjuicio de la ciudad vecina y viceversa.

\section{COMPLEMENTACIÓN ECONÓMICA}

Sin duda alguna, cada Estado tiene el legítimo derecho de promover el desarrollo de sus áreas de frontera, pero también es importante el fomento de relaciones de cooperación y complementación económica que redunden en beneficios recíprocos de las zonas fronterizas de países limitrofes.

Las estrategias de desarrollo de las respectivas zonas de frontera debieran considerar, no solamente medidas desde 'dentro', sino también desde 'fuera', propiciando las condiciones institucionales, económicas, sociales y culturales para una estrecha interrelación e interdependencia beneficiosa para ambas partes.

En el caso de Perú y Chile, las ciudades de Tacna y Arica debieran consolidar su espacio fronterizo común, mediante acciones conjuntas y coordinadas, orientadas a un desarrollo mutuo, en vez de mantener latentes, antiguos "resentimientos» patrióticos que son utilizados para otros fines, distintos a los de la integración fronteriza.

Ambas fronteras se encuentran conectadas por la carretera Panamericana, con un servicio eficiente de transporte de carga y de pasajeros entre ambos paises y, por via ferroviaria, a cargo de la empresa estatal peruana ENAFERPERU.

En los últimos años, se han venido ejecutando una serie de acciones que, en algún modo, han servido para fomentar la integración y cooperación entre las ciudades fronterizas de Tacna y Arica, entre las cuales destacan las siguientes:

- Existen acuerdos y convenios que regularmente se discuten a nivel de la subcomisión mixta peruano-chilena, integrada por las autoridades representativas de Tacna y Arica, referidos especialmente al tránsito de mercaderias, vehiculos y personas.

- Por parte del sector privado, se han organizado algunos encuentros empresariales que han mostrado la buena voluntad e intención de fomentar la interrelación productiva y comercial entre los distintos sectores económicos que operan en las zonas de frontera.

- Asimismo, se han efectuado eventos de intercambio cultural y ferias artesanales, 
denominados Semana de Tacna en Arica y Semana de Arica en Tacna, los cuales se llevan a cabo anualmente.

- En el campo de la salud, se han celebrado reuniones y acuerdos bilaterales sobre la prevención y control de enfermedades infectocontagiosas, como por ejemplo, el caso del cólera.

- De otro lado, se ha venido impulsando la cooperación policial en materia de 'contrabando', a través de la cual, los cuerpos policiales de ambos países coordinan acciones para un efectivo control y represión del internamiento ilegal de productos por la frontera. Dicha cooperación se extiende a un convenio para combatir el tráfico ilícito de drogas por la línea de frontera.

- Otro avance importante se da en la cooperación en materia de control fito y zoosanitario. Destaca el convenio MOSCAMED para combatir la mosca de la fruta que viene obteniendo buenos resultados.

Sin embargo, hay muchas otras actividades y proyectos que podrian fortalecer las relaciones de complementariedad entre las dos zonas fronterizas, que históricamente han conformado un solo espacio regional geoeconómico, el mismo que fue interrumpido por conflictos bélicos entre ambos países en el siglo pasado y cuyas secuelas lamentablemente hasta hoy perduran, en detrimento de las cordiales relaciones que deberian prevalecer entre ambos pueblos.

A continuación, se recogen algunas propuestas, que han sido sugeridas y que podrian ser aplicadas en el proceso de integración fronteriza peruanochileno:

- Regular y facilitar el intercambio comercial de menor cuantía que de manera espontánea e

\section{BIBLIOGRAFIA}

AGREDA, J. La integración fronteriza en la subregión andina. Instituto Internacional de Integración. La Paz, 1985.

BID/INTAL Identificación, preparación y evaluación de proyectos de integración fronteriza. Buenos Aires, 1989.

BOISIER, S. Notas en torno al desarrollo de regiones fronterizas en América Latina. ILPES, 1986.

CORFO ARICA. Plataforma de negocios. Santiago de Chile, Marzo de 1995.

Plan de acción para impulsar el desarrollo de la zona de Arica. 1995. inclusive informalmente, se realiza desde hace varias décadas.

- Promover la inversión privada binacional en los centros manufactureros tanto en el Parque Industrial de Tacna como en el Parque ! Iustrial de Chacalluta (Arica), utilizando preferentemente la oferta productiva regional de las zonas fronterizas.

- Promocionar el turismo receptivo a través de la oferta de circuitos y paquetes turisticos binacionales de beneficio compartido.

- Organizar ferias comerciales de integración fronteriza tanto en Tacna como en Arica, periódicamente.

- Interconectar los sistemas eléctricos del sur peruano y el norte chileno para complementar la cobertura de la creciente demanda de energía.

- Propiciar en el campo educativo un mayor entendimiento para el intercambio docente y estudiantil y para la ejecución de proyectos de investigación científica y tecnológica conjunta sobre temas de interés común.

- Atender en los puestos de control fronterizo durante las 24 horas del dia, para dar mayor fluidez al numeroso tránsito de personas y mercaderias que se movilizan entre Tacna y Arica.

- Institucionalizar las actividades y proyectos de cooperación binacional, mediante la conformación de un comité de Frontera, con funcionamiento permanente y constituido por autoridades públicas, representantes de las principales organizaciones privadas, sociales y académicas, ligadas al desarrollo de las zonas de frontera.

INE

Informativo estadístico regional. I Región Tarapacá Informativo Anual 1993.

PROCHILE Consejos básicos para exportar.

ZEBALLOS, W. Evaluación de la Zotac. Universidad Nacional Jorge Basadre Grohmann. Tacna, 1994.

ZEBALLOS, W. Zotac y el desarrollo de la frontera Sur. Ponencia presentada al XI Congreso Nacional de Economistas del Perú. Arequipa, 1993.

ZOFRI Ley de Zonas Francas. Reglamento Interno Operacional. ¿Qué es ZOFRI?. Parque Industrial ZOFRI Arica

ZOTAC Guia del inversionista. Cuarta Versión. Tacna, 1996 